\title{
Total Assembly Construction Technology of Ultra-long Variable Cross-section Spiral Aluminum Plate Unit of Qingdao Citizen Fitness Center Sports Stadium
}

\author{
Yong Liang, Zhiyan Che*, Xinyou Chen, Cipei Liu \\ China Construction Shenzhen Decoration Co Ltd, Shenzhen, China \\ Email address: \\ ideadance@163.com (Yong Liang),7959025@qq.com (Zhiyan Che), xiaoxin.584521@qq.com (Xinyou Chen), \\ luici002@qq.com (Cipei Liu) \\ ${ }^{*}$ Corresponding author
}

\section{To cite this article:}

Yong Liang, Zhiyan Che, Xinyou Chen, Cipei Liu. Total Assembly Construction Technology of Ultra-long Variable Cross-section Spiral Aluminum Plate Unit of Qingdao Citizen Fitness Center Sports Stadium. Engineering and Applied Sciences. Vol. 4, No. 5, 2019 , pp. 98-104. doi: $10.11648 /$ j.eas.20190405.12

Received: August 2, 2019; Accepted: September 11, 2019; Published: September 25, 2019

\begin{abstract}
Qingdao Citizen Fitness Center Sports Stadium is saddle-shaped with a construction area of about $140,000 \mathrm{~m}^{2}$. The rippled roof and façade are assembled with ultra-long variable cross-section spiral aluminum plate units. The largest aluminum plate unit is 1.5 tons heavy and 13 meters long. The main structure of this project is the steel structure that can deform due to the factors such as temperature and subsidence, thus making it difficult to accurately install the aluminum plate curtain wall. During construction, the total station is used several times for data acquisition to generate the BIM model, which is aligned, compared and analyzed with the theoretical 3D model for providing the accurate support for the construction process. A 1:1 main truss of the steel structure is erected on the façade to simulate the tire frame erection and assembly the ultra-long variable cross-section spiral aluminum plate units on site. The main steel structure, with the lowest point at 26 meters and the highest point at 49 meters, is lifted by the truck cranes and inserted for installation from up to down. This process is a new curtain wall construction method that increases the installation efficiency by $30 \%$, improves the construction quality and guarantees the construction safety. It can provide the technical reference for the curtain wall work of other similar large sports stadium projects in the future.
\end{abstract}

Keywords: Variable Cross-Section Spiral Aluminum Plate, Ground Assembly, Overall Lifting, Setting-Out by Robotic Total Station

\section{Project Introduction}

Qingdao Citizen Fitness Center Sports Stadium is located in the west of Aodong Road, south of Shuangji Road in High-tech Zone. It has a construction area of about $140,000 \mathrm{~m}^{2}$, with a stand, a sports ground, an audience lounge hall (corridor), game rooms, equipment rooms, reception rooms, lounges, offices and auxiliary commercial rooms. The stand may accommodate 60,000 audiences. After completion, it becomes the main venue for Shandong Sports Games in 2018.

The sports stadium is saddle-shaped, and the roof and the façade show a "rippled texture". The saddle shape matches the morphological feature of large sports stadium that has a stand high in the east-west direction and low in the south-north direction, thus being able to meet the functional needs and avoiding waste of space. The uniform texture design ensures the integrity and simplicity of the shape. The obliquely flowing rippled texture creates a dynamic effect like the wind blowing on the sea surface and perfectly displays the concept of "Sand of Sea".

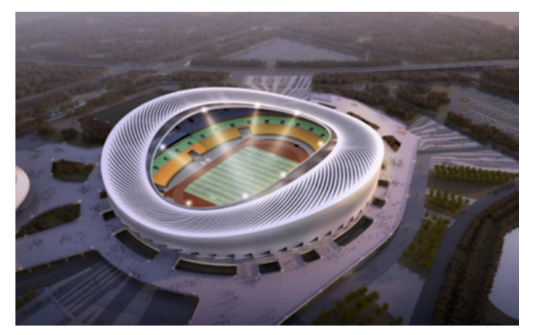

Figure 1. The architectural effect of "Sand of Sea" of Qingdao Citizen Fitness Center Sports Stadium. 


\section{Analysis of Technical Difficulties of Construction}

1) The main shape of the aluminum plate curtain wall is an ultra-long variable cross-section spiral ascending curve unit. After fabrication, the maximum weight of the aluminum plate truss is 1.5 tons, and the maximum length of the aluminum plate unit is $13 \mathrm{~m}$ [1]. It is a new structural form of curtain wall without well-developed previous experience of installation in the industry. The difficulty points for construction are how to effectively organize the construction, efficiently and accurately locate and control the forming of aluminum plate surface at a time.

2) The key points for this project comprise differences in line width, angle and radian of aluminum plate, inconsistent height coordinates of connecting points of auxiliary steel structure and main steel structure, and the methods of measurement, setting-out and material ordering.

3) The main structure of this project is the steel structure, which may deform due to the factors such as temperature, subsidence and quality change after installation of the auxiliary structure of the curtain wall. How to minimize the impact of structural deform during the installation of the aluminum plate is a key point for the aluminum plate installation quality control of this project [2].

\section{Key Construction Technologies}

\subsection{Construction Process}

Measurement and setting-out by RTS robotic total station and data processing $\rightarrow$ installation of auxiliary steel structure at the base $\rightarrow$ erection of a tire frame and a platform in the workshop $\rightarrow$ assembly of aluminum plate unit keel $\rightarrow$ installation of aluminum plate $\rightarrow$ lifting of aluminum plate unit $\rightarrow$ adjustment of the aluminum plate unit.

\subsection{Measurement and Setting-Out by RTS Robotic Total Station}

(1) Measurement and setting-out by RTS robotic total station are mainly used in the following three phases

1) RTS robotic total station is used for data acquisition of the main structural steel truss of the curtain wall. The BIM model visible from data after field scanning is aligned and collided with the architectural theoretical 3D model to analyze deviation, adjust BIM architectural model and ensure accuracy of base structure ordering with BIM [3].

2) The impact of the installation of the auxiliary structure of curtain wall on the deformation of the main steel structure is monitored in this process. After completion, the second data acquisition is conducted to the base structure to adjust the BIM model data and offer a guarantee for the ordering of aluminum plates.

3) After installation of the aluminum plate, the third data acquisition is conducted to the aluminum plate surface, which is adjusted after model comparison. Following the third data acquisition and analysis, the construction staff is provided with clarification and then a final adjustment is made.

(2) Processing of measured data

The structural measurement data is processed, the origin of the coordinate of the construction $\mathrm{CAD}$ drawing is identical to the origin of the coordinate of the surveying control network. Then the processed data are imported into the BIM model to clearly get the deviation information of the main structure. Such information is very important for theoretical ordering. If the structural elevation and the left and right deviation are within the scope absorbed by the curtain wall system (e.g. $\pm 20 \mathrm{~mm})$ [4], the construction requirements may be satisfied. if the elevation exceeds the absorption scope, the adapting piece for prolongation or shortening may be used for achieving the installation.

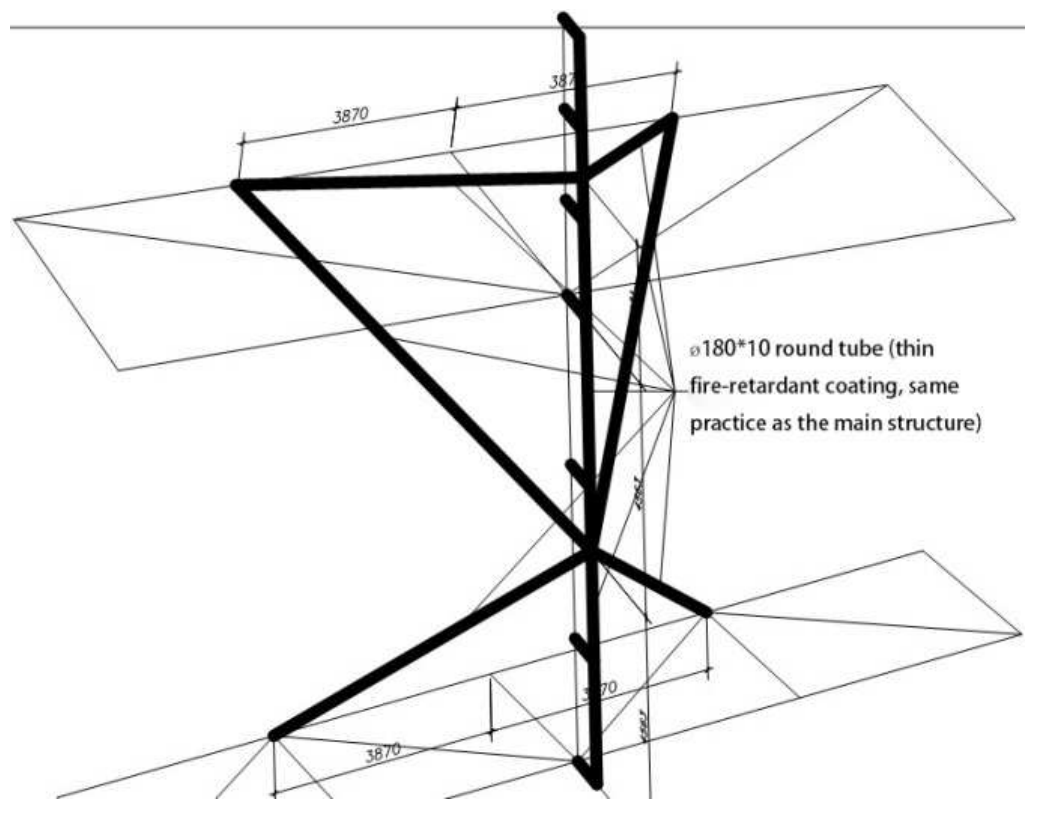

Figure 2. Axonometric drawing of auxiliary steel structure. 


\subsection{Installation of Auxiliary Steel Structure at the Base}

All connecting points of the aluminum plate curtain wall are located on the auxiliary steel structure and transmit force to the main steel structure. The auxiliary steel structure is a $ø 180 * 10$ round tube welded to the main steel structure by adapting piece. The auxiliary steel structure is processed and installed according to the length required by the BIM model after the first setting-out and adjustment, to ensure that the aluminum plate curtain wall can be located and fabricated totally in accordance with the model.

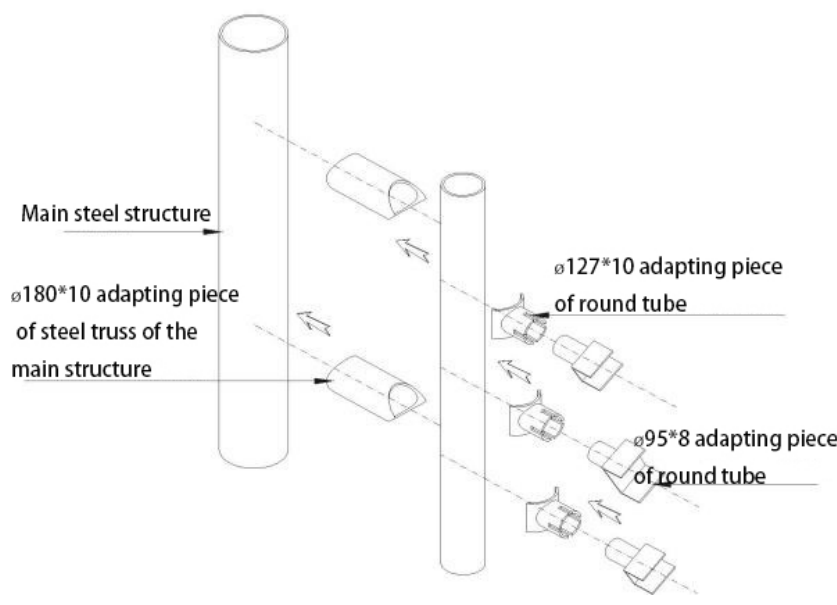

Figure 3. Sequence of installation.

\subsection{Erection of Tire Frame and Platform in the Workshop}

1) Tire frame erection

The platform erection should base on the second data acquisition with 1:1 field setting-out, locating 13 control coordinates. A $ø 180 * 10 \mathrm{~mm}$ steel truss of the main structure on façade is simulated on the tire frame erection area [5]. A $ø 180 * 10 \mathrm{~mm}$ round tube is used vertically, cut according to Z-axis height and welded for fixation, so as to achieve the simulation field of tire frame erection. During erection, the RTS robotic total station is utilized for verification and fixation of the $\varnothing 180 * 10 \mathrm{~mm}$ steel truss of the main steel structure. The vertical fixation is realized by the welded support at the bottom of the round tube. Diagonal bracing is welded laterally to prevent eccentricity and displacement of the fixing round tube and ensure the overall dimension of the tire frame [6].

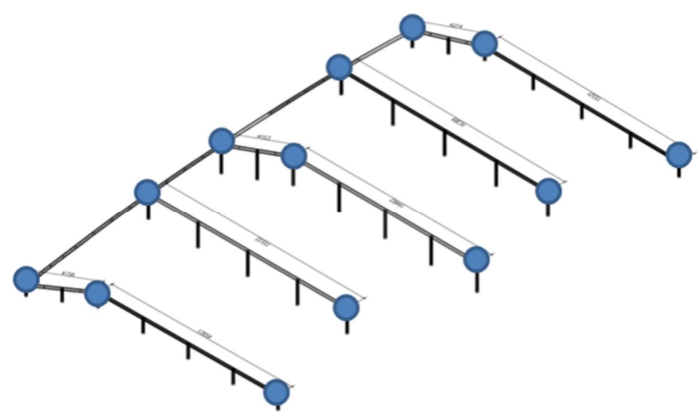

Figure 4. Tire frame erection (13 control points).

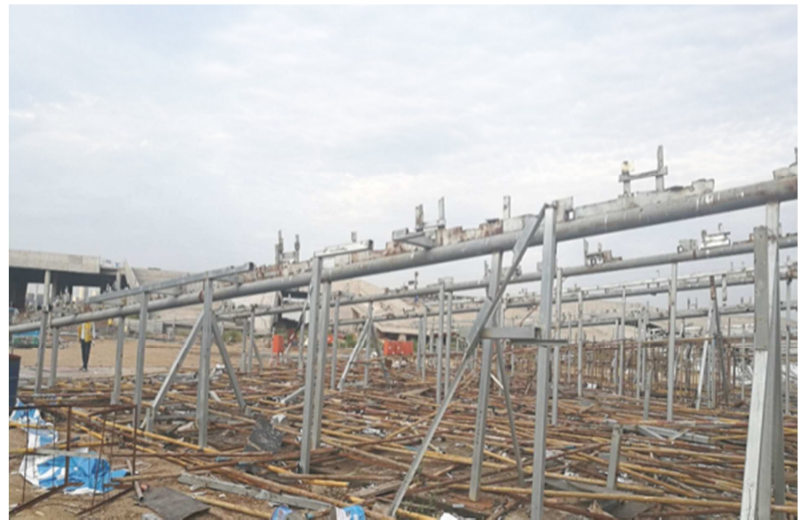

Figure 5. Tire frame erection field.

\section{2) Erection of operating platform}

The operating platform is a full scaffold laid with $5 \mathrm{~cm}$ wood plates and bound by steel wires. There is $1100 \mathrm{~m}$-high maintenance railing around. The bottom height of scaffold is $1800 \mathrm{~mm}$ and slopes upward at $7^{\circ}[7]$. The operating platform height should ensure the normal operating height of workers.

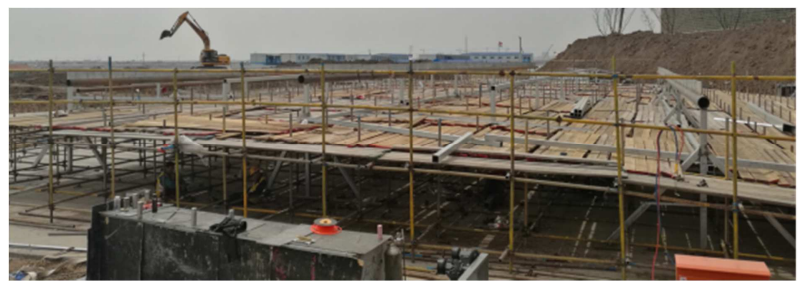

Figure 6. Operating platform.

\subsection{Assembly of Aluminum Plate Unit Keel and Truss}

In order to accelerate the field installation, the keel of the aluminum unit is semi-assembled and fabricated on the field tire frame. The steel frame is divided into left mullion, middle mullion and right mullion.

The keel points of the aluminum plate curtain wall are extracted from BIM after adjustment of the second setting-out data, so as to locate the main keel of the aluminum plate and then weld and assemble the curtain wall keel.

(1) Single tube tailor welding and assembly, control of bending radian

A ground of mullions is composed of 2 to 3 sections of 200x200x10mm arc steel square. After being bent and processed, the steel square is assembled and processed according to the single tube assembly drawing, and then the bevel cutting is conducted at the end. During assembly, 2 to 3 sections of steel tubes are socket welded by the hot-dip galvanized steel core insert.

Two days after bending steel squares, check the degree of curvature for the second time and make correction promptly if the error is more than $5 \mathrm{~mm}[8]$.

(2) Setting-out, locating and verification of steel truss

The steel truss is fabricated according to the BIM model data; and the RTS robotic total station is used for truss locating and verification of truss, including: locating the center points of $200 \times 200 \times 10 \mathrm{~mm}$ steel square and aluminum 
plate fixing angle steel, the arch height of the aluminum plate fixing angle steel, and the center point of $100 \times 100 \times 4 \mathrm{~mm}$ steel square, and verification of all points to avoid installation error.

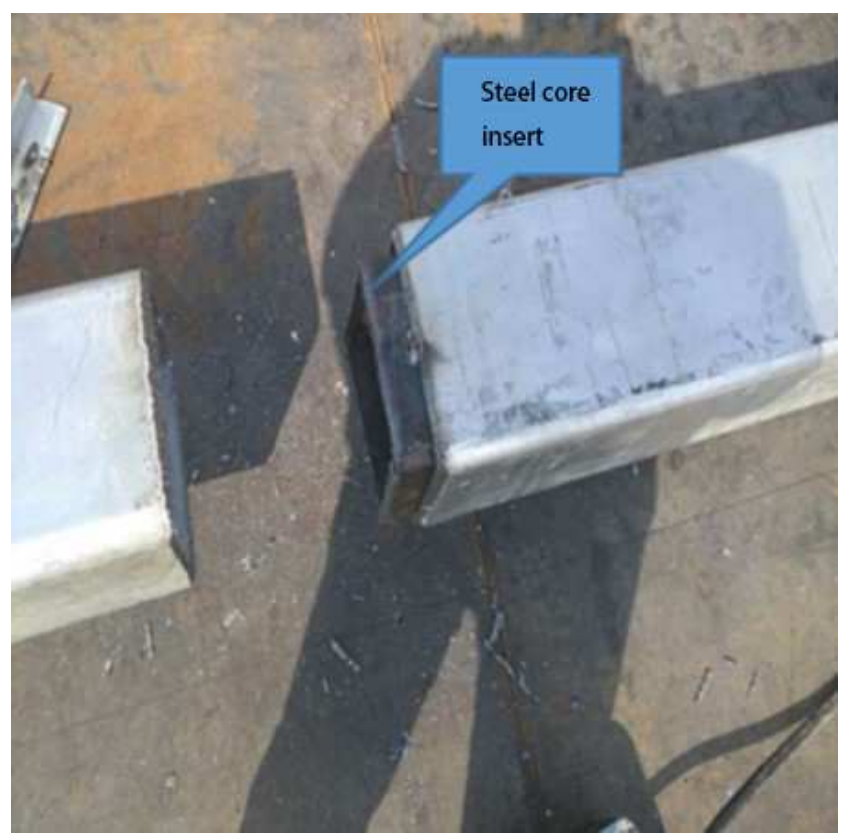

Figure 7. Steel core insert for steel tube assembly.

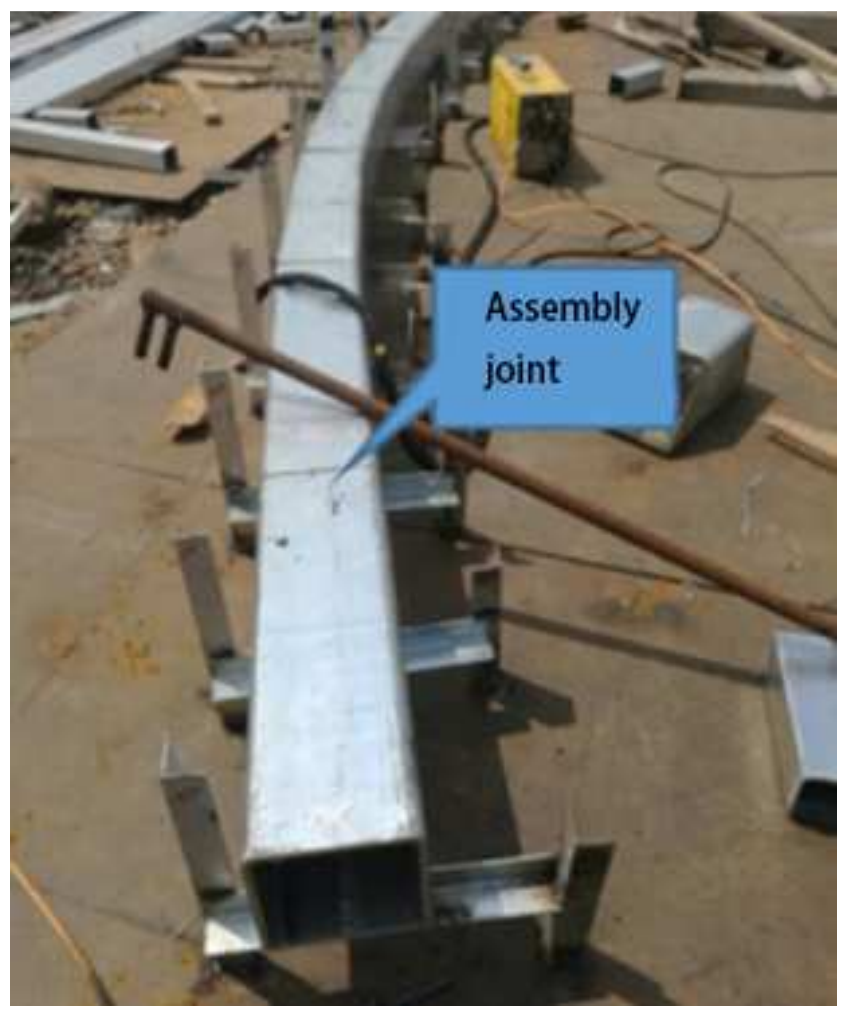

Figure 8. Steel tube assembly.

(3) Assembly of steel truss keel

a. Locate the center point at the upper opening of the $200 \times 200 \times 10 \mathrm{~mm}$ steel square, fix by laying steel square from the door arch upwards, chamfer the steel end during welding of the steel square by V-shaped groove welding; b. Two pieces of $12 \mathrm{~mm}$ thick steel plates are connected by M16 bolts to be a whole [9]; and the end opening is welded and plugged by a steel plate to prevent intake of water.

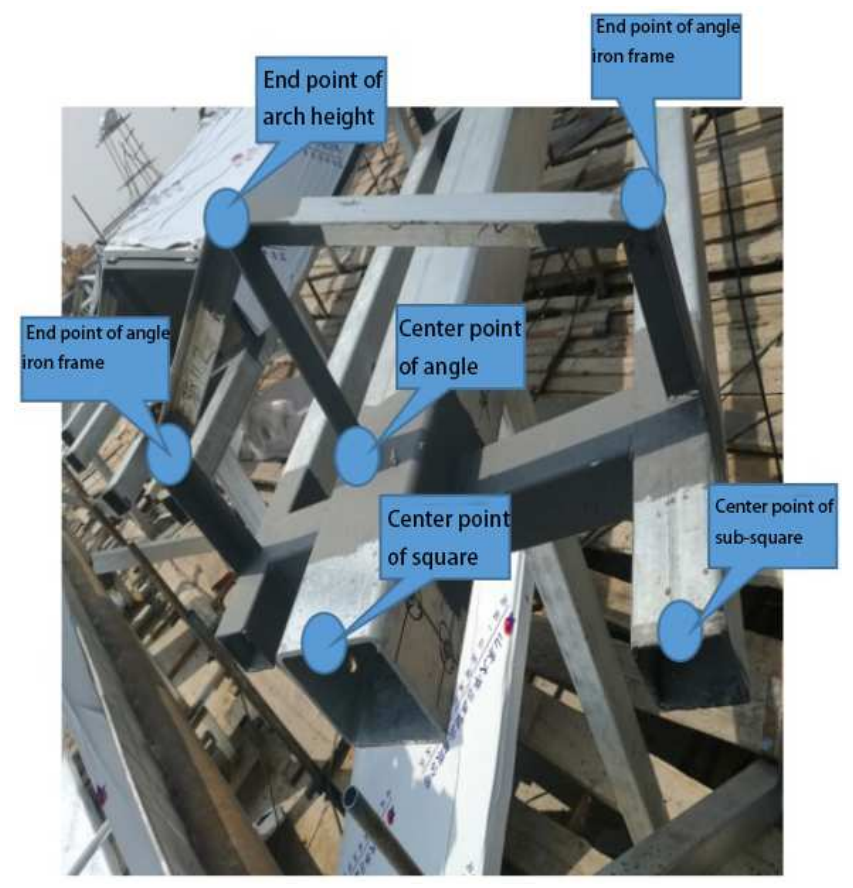

Figure 9. Dimensional control and setting-out of steel truss.

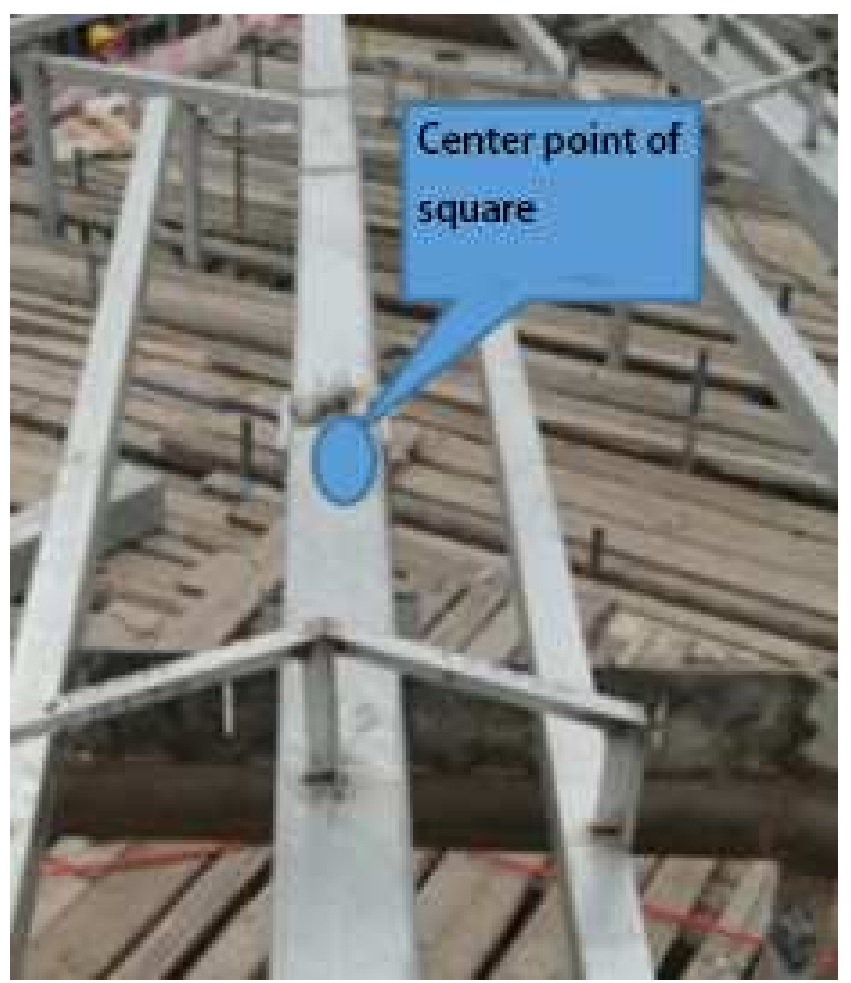

Figure 10. Steel truss square laying.

c. Lay the upper and lower $100 \times 100 \times 4 \mathrm{~mm}$ steel squares and fix them temporarily;

d. The control lines are plotted for the fixing frame of an aluminum plate on the assembly steel platform, and then the welding and machining are carried out after comparison of 


\section{dimension;}

e. The angle steel position of the aluminum plate is controlled pursuant to the restriction point and welded with the upper and lower $100 \times 100 \times 4 \mathrm{~mm}$ steel squares for fixation [10].

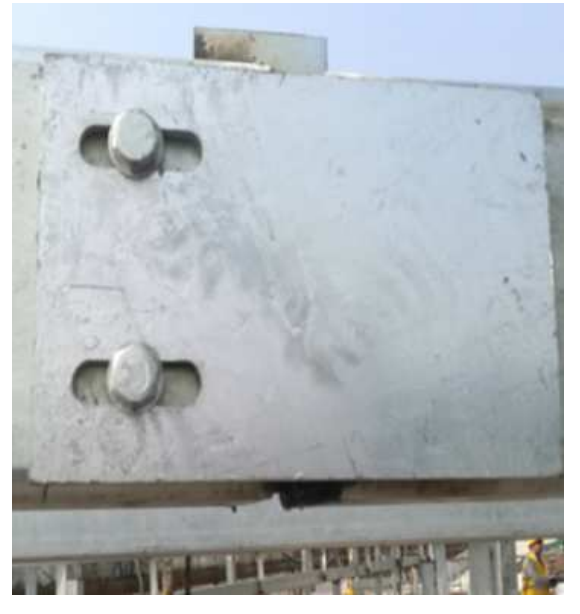

Figure 11. Steel truss square connection.

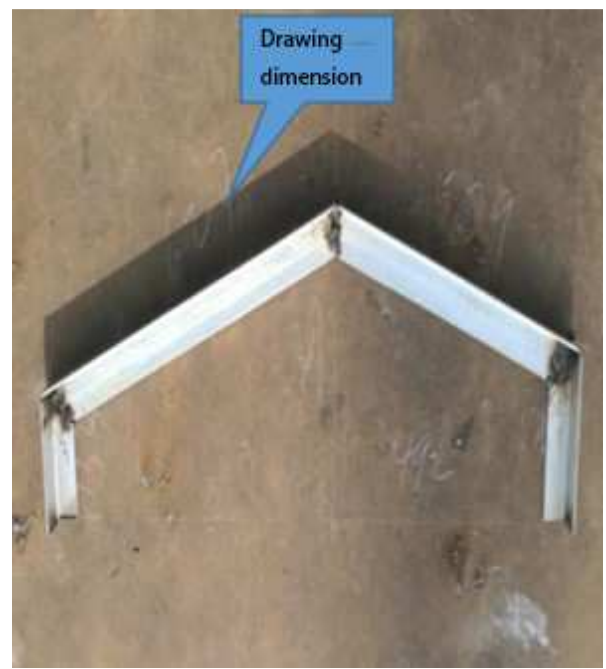

Figure 12. Machining of fixing angle steel of aluminum plate.

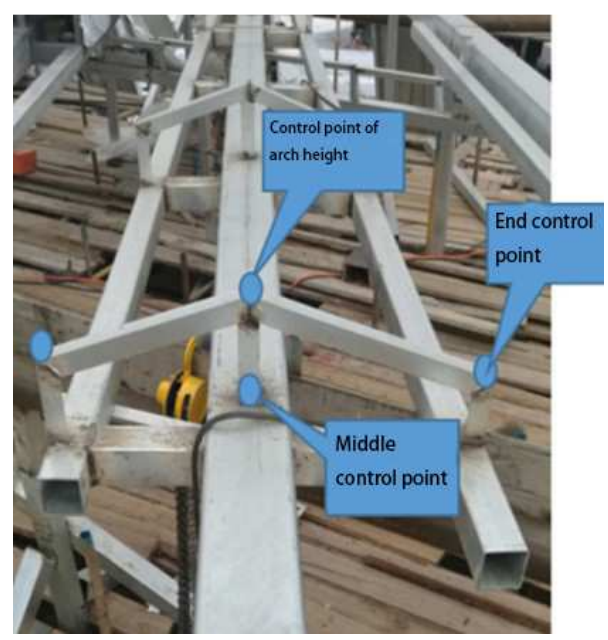

Figure 13. Fixation of fixing angle steel of aluminum plate. f. The upper and lower $100 \times 100 \times 4 \mathrm{~mm}$ steel squares are adjusted and fixed according to the positions of the angle steel frame;

g. The lateral $100 \times 100 \times 4 \mathrm{~mm}$ supporting squares are welded with a clearance of $3-5 \mathrm{~mm}$, by means of I-shaped welding [11];

h. Anti-corrosion treatment (two times of epoxy zinc-rich anti-rust primers, two times of epoxy micaceous iron oxide anti-rust intermediate paint, two times of top coats).

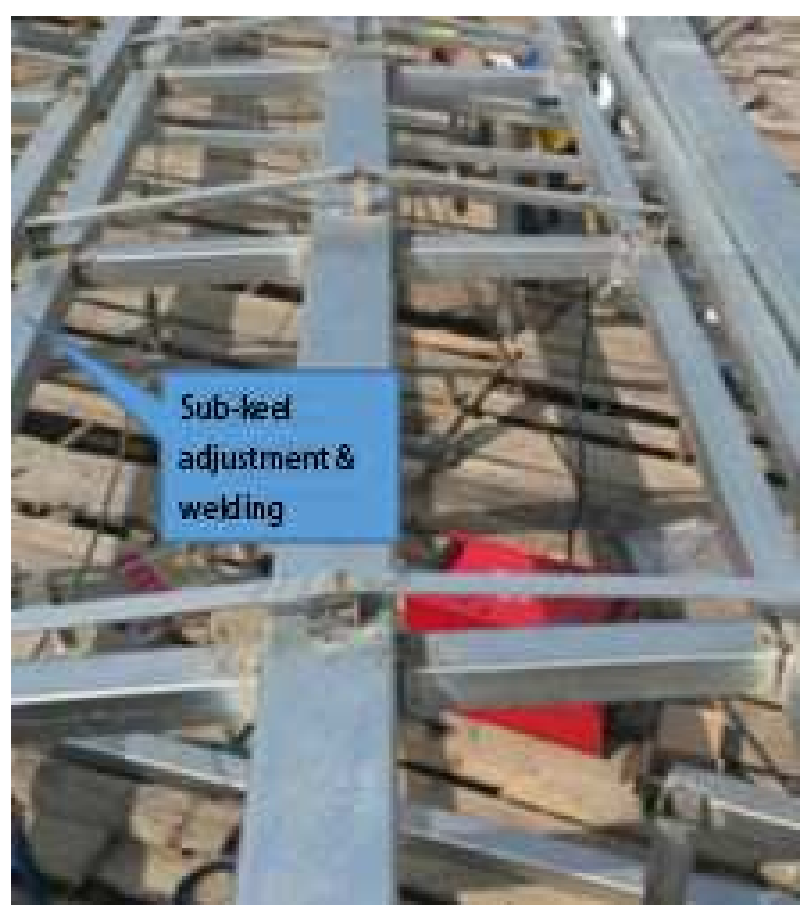

Figure 14. Installation of fixing angle steel of aluminum plate.

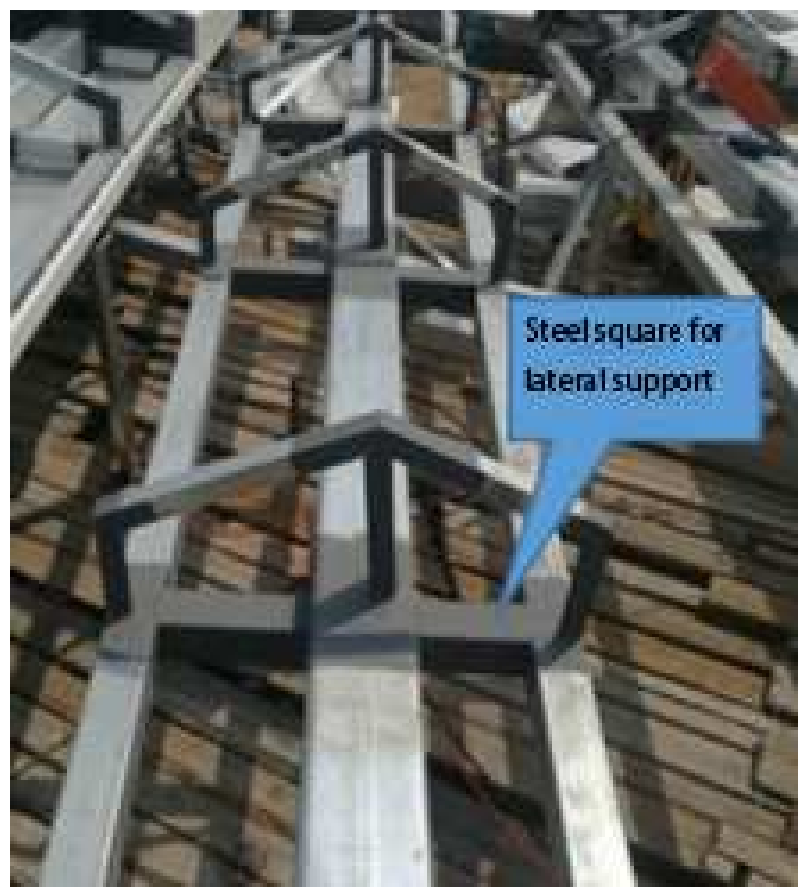

Figure 15. Completion of steel truss. 


\subsection{Installation of Aluminum Plate}

The aluminum plate is fixed on the truss. In order to ensure the stableness and smoothness, the closed joint of the aluminum plate should be pinned as required, and installed by inserting the pins from bottom to up;

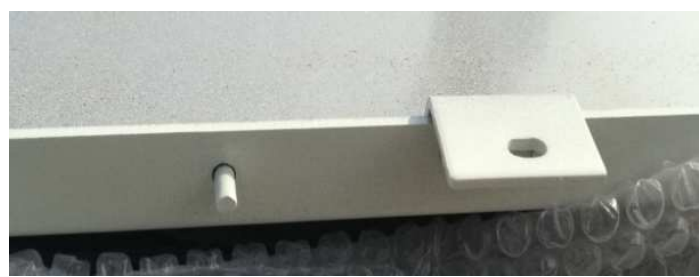

Figure 16. Aluminum plate pin

The aluminum plate unit has closed joints and glued joints, which are installed according to the numbering of the aluminum plate during construction;

The angle bracket of the aluminum plate has joints, the aluminum strips are installed to ensure the fixedness of aluminum plates, and a rubber pad is needed under the angle bracket of the aluminum plate if there are joints at the fixing point of the angle bracket of the aluminum plate;

Fasteners are used to fasten the angle bracket of the aluminum plate and fix with the stainless steel self-tapping screw. Before gluing the aluminum plate, the masking tape must be pasted to prevent pollution of the aluminum plate surface [12].

\subsection{Lifting of the Aluminum Plate Unit}

The maximum weight of the processed truss of the aluminum plate unit is 1.5 tons, and the maximum length of the aluminum plate unit is $13 \mathrm{~m}$; the lowest point of the main steel structure of sports stadium is $26 \mathrm{~m}$, and the highest point is $49 \mathrm{~m}$. 25T and 50T truck cranes are used for lifting [13];

The unit element is lifted in sequence from door arch to upwards.

The aluminum plate unit has two manual hoists temporarily fixed to the auxiliary steel structure of the curtain wall and adjustments are made by extracting points in the BIM model and the field measurement and setting-out. After proper adjustment, the custom adapting piece is used to fix the aluminum plate unit to the auxiliary steel structure of the curtain wall. The adjusting bolts and limiting steel plates are used between single aluminum plate units for position limitation and fixation, with the functions of expansion joints.

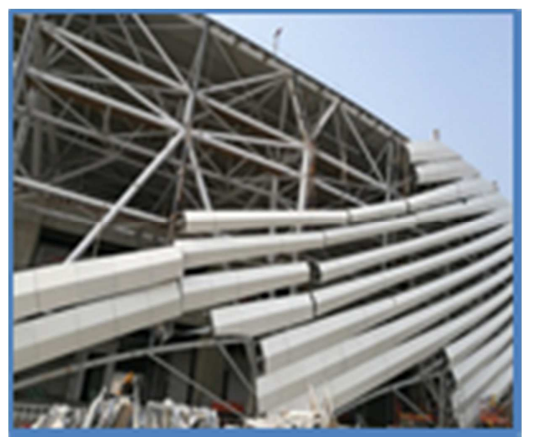

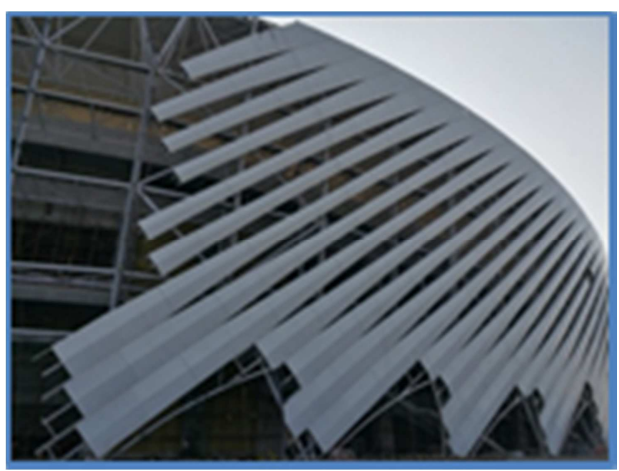

Figure 17. Aluminum plate unit lifting.

It is fixed by spot welding after adjustment, and then fully welded after the RTS robotic total station verifies the end control points;

Key points for lifting:

1) The protective measures for the safety of work at heights should be strictly implemented during lifting, and a full-time safety staff shall be arranged for patrolling;

2) Attention should be paid to the protection of finished products during assembly, lifting and transportation of the aluminum plate unit, and avoiding damage of aluminum plates by friction [14];

3) During the transportation, the aluminum plate units should be put on wood and firmly bound by strips to prevent falling of blocks;

4) A wind-proof rope is used laterally with a directional slide rail to prevent tilt and sway. If the wind scale is level 5, stop lifting;

5) Warning lines are drawn during lifting of the unit element to prevent pedestrians and personal injury due to falling.

6) When the aluminum plate unit is welded and fixed, a fireproof cloth is laid to prevent from being burnt by the aluminum plate;

7) After installation, the RTS robotic total station is used to scan the overall installation area. The scanned data are compared with the BIM model. If there is deviation, the slight panel adjustment is conducted by adjusting rubber pads of the aluminum plate.

\section{Conclusions}

The total assembly construction technology of ultra-long variable cross-section spiral aluminum plate units applies the RTS robotic total station and the BIM technology in the entire process of setting-out, installation, adjustment and deformation monitoring. Through erecting a $1: 1$ simulated façade of $ø 180 * 10 \mathrm{~mm}$ main structural steel truss on the site, the simulated field of the tire frame erection can be achieved to divide the aluminum plates into batches and units [15]. They are assembled on the ground and then lifted as a whole, thus ensuring the construction safety, obviously accelerating the installation speed and improving work efficiency while guaranteeing construction quality. This technology may provide a reference for the installation of exterior curtain 
walls of large venues with the complex variable cross-section aluminum plate shape under the influence of the assembly and modularized construction in the future.

\section{References}

[1] Ministry of construction of the People's Republic of China, JGJ 80-2016 technical specification for safe operation at height during construction [S], China planning press, 2016.

[2] Ministry of housing and urban-rural development of the People's Republic of China, jgj59-201 construction safety inspection standard [S]. Beijing: China building industry press, 2011.

[3] Ministry of housing and urban-rural development of the People's Republic of China, gb50017-2003 steel structure design specification [S]. Beijing: China standard press, 2017.

[4] General administration of quality supervision, inspection and quarantine of the People's Republic of China, TSG q5001-2009 regulations for the use of lifting machinery [S]. China standard publishing house, 2009.

[5] Standardization Administration of China. GB/T 21086-2007 Curtain wall for building [S]. Qinhuangdao: Standards Press of China, 2008.

[6] Ministry of Construction of the People's Republic of China. JGJ 131-2001 Technical code for metal and stone curtain walls [S]. Beijing: Standards Press of China, 2001.

[7] Ministry of Construction of the People's Republic of China. JGJ 102-2003, J 208-2003 Technical code for glass curtain wall engineering [S]. Beijing: Standards Press of China, 2003.
[8] Ministry of Housing and Urban-Rural Development of the People's Republic of China. GB 50009-2012 Load code for the design of building structures [S]. Beijing: China Architecture \& Building Press, 2012.

[9] Ministry of Housing and Urban-Rural Development of the People's Republic of China.. JGJ/T 104-2011 Specification for winter construction of building engineering $[\mathrm{S}]$. Beijing: China Architecture \& Building Press, 2011.

[10] Liu pan, zhang jing. Application of BIM technology in curtain wall decoration engineering [J]. Shandong industrial technology, 2018, (11): 113, 101.

[11] Ma guihong. Construction technology of variable section aluminum curtain wall for irregular construction single $[\mathrm{J}]$. Construction technology, 2016.

[12] Su Hang, Nie Jixing, Yu Pei, Huang Chao, Wan Hongwei. Construction technology of hyperboloid triangular concave-convex aluminum curtain wall $[\mathrm{J}]$. Construction technology, 2015 (6).

[13] Jiang Zhiqiang. On the Construction Technique of Special-shaped Curtain Walls in Large Buildings [J]. Decoration Refurbishment Chntre, 2015 (9).

[14] Huang Jiawen. On the Application of BIM Parameterized Technique in the Special-shaped Curtain Walls [J]. Architectural Engineering Technology and Design, 2017 (14): 373-374.

[15] Wen Changjuan and Ma Peng. Installation Technique of Curved Honeycomb Aluminum Plate Curtain Walls in Large Stadiums [J]. Sichuan Architecture, 2015 (12): 204-205. 